\title{
Evaluation of Silica-Coated PCC as New Modified Filler for Papermaking
}

\author{
Ana F. Lourenço, José A. F. Gamelas,* Christin Zscherneck, and Paulo J. Ferreira* \\ CIEPQPF, Chemical Engineering Department, University of Coimbra, Pólo II, R. Sílvio Lima, 3030-790 Coimbra, Portugal
}

\begin{abstract}
Silica-coated precipitated calcium carbonate (PCC) prepared by a sol-gel method in a previous study, was used, for the first time, as filler for papermaking. Three samples of modified PCC, containing 11, 21, and 29 wt \% of silica, were prepared. The handsheets produced with a eucalyptus kraft pulp furnish containing the new PCC-based materials showed better paper strength properties than those with the unmodified PCC, whereas the structural properties and brightness were not affected (for similar filler retention values (ca. 80\%)). The results suggest that a thin film of silica coating the calcium carbonate crystals has a positive impact on the filler-to-fiber-to-filler bonding. This may open a new possibility to increase the filler amount in the papermaking industry.
\end{abstract}

\section{INTRODUCTION}

Precipitated calcium carbonate (PCC) is becoming the most common filler for the production of printing and writing fine papers. As filler it contributes to reduction of the fiber content, thus decreasing the dependence on forestry resources, and it promotes drainage and drying in the paper machine, with clear benefits in terms of costs. On the other hand, some paper enduse properties, such as brightness, opacity, gloss, smoothness, and printability are usually enhanced and its impact is often superior to that of other fillers. However, as expected, the calcium carbonate mineral particles cause a decrease in fiber bonding, which leads to a reduction of the paper strength. Additionally, it increases the demand of internal sizing agents and the phenomena of abrasion, dusting, and bad filler retention. Therefore, the filler content in paper is limited to values usually not greater than $25 \% .^{1-3}$

To overcome these drawbacks and increase the filler content without significantly sacrificing the paper mechanical resistances some treatments/modifications of the filler surface have been suggested. Precipitated calcium carbonate has been treated/modified by organic compounds such as starch, starch derivatives, carboxymethylcellulose, xanthan gum, water-soluble synthetic polymers, and polymer latexes, among others. ${ }^{4-13}$ For instance, Gill ${ }^{11}$ reported that the PCC modification by surface treatment with a cationic polymer improved the filler retention in the furnish and reduced the usage of wet sizing agent without losses in tensile strength and sheet brightness. In another study, an increase of Scott bond and breaking length was found for handsheets produced with the PCC treated with anionic polysaccharides (xanthan gum and anionic guar gum).$^{10}$ From all the results reported in the literature, the most promising are those related to the modification of the PCC surface using starch. $^{3-7}$ The handsheets produced with starch gel-coated PCC showed much better tensile strength than those produced from unmodified PCC, while the optical properties were not significantly affected. ${ }^{4}$ The use of different types of starch (corn, potato, and modified starch) had no significant impact on the results. Recently, Laleg treated the PCC particles with anionic polymer dispersions (latex) and found that the resultant slurries could improve filler retention (based on turbidity results), sizing performance, and paper strength besides improving acidresistant properties of filler in papermaking. ${ }^{12}$

Some work has been developed using formulations containing inorganic compounds such as calcium-chelating agents (e.g., sodium hexametaphosphate), weak acids (e.g., phosphoric acid), aluminum salts (e.g., aluminum chloride), zinc chloride, and sodium silicate. ${ }^{14-23}$ It should be noted that some authors claimed the preparation of silica-coated calcium carbonate when using in fact sodium silicate. ${ }^{15,16,20}$ Most of these treatments were directed to obtain calcium carbonatebased filler with improved acid-resistant properties which are required for papermaking in weakly acid to neutral conditions. Nevertheless, just a few studies include the evaluation of the impact of the treated fillers on the papermaking mechanical properties. $^{3,22,23}$ In general, when comparing the handsheets made with the inorganics-treated fillers vs those based on the untreated filler, typically mechanical properties (tensile index, burst index) have not improved, but a few optical properties such as brightness and, in some cases, the light scattering coefficient have been enhanced.

Recently, the authors of the present paper reported the production of silica at the surface of PCC by hydrolysis of tetraethyl orthosilicate (silica precursor) in ethanol/water solutions under alkaline conditions. ${ }^{24}$ In the new isolated materials it was proved that silica was fixed to the PCC particles in the form of a film and that the amount of silica in the new materials could be controlled based on the ammonia concentration of the reaction medium, among other factors. It was suggested that hydroxyl groups present at the surface of silica-coated PCC could provide stronger physical interactions with the cellulosic fibers than those observed with unmodified PCC and thus could improve fiber-filler interactions and paper strength. In this article, and in order to confirm this hypothesis,

Received: December 20, 2012

Revised: January 31, 2013

Accepted: March 12, 2013

Published: March 12, 2013 
we report for the first time the application of silica-coated PCC (produced by sol-gel method) as filler to produce paper.

\section{EXPERIMENTAL SECTION}

2.1. Materials, Methods, and PCC Modification. An aqueous suspension of an industrial scalenohedral PCC was filtered using a Buckner filter $(0.2 \mu \mathrm{m})$ and the solid obtained was oven-dried at $105{ }^{\circ} \mathrm{C}$ for $24 \mathrm{~h}$. From the thermogravimetric analysis the amount of calcium carbonate in the particles (wt $\%)$ was obtained by considering the decomposition of $\mathrm{CaCO}_{3}$ to $\mathrm{CaO}$ accompanied by the release of $\mathrm{CO}_{2}$ : [weight loss $\left.\left(580-900{ }^{\circ} \mathrm{C}\right) \times 100.1 / 44.0\right]$. It was found that PCC is constituted by ca. $95 \mathrm{wt} \%$ of calcium carbonate and $5 \mathrm{wt} \%$ of other components (here called impurities, for simplification).

The silica-coated PCC particles were obtained from dry PCC, tetraethyl orthosilicate (TEOS), water, ethanol, and ammonia as previously reported in detail by Gamelas et al. ${ }^{24}$ Experiments with $\left[\mathrm{NH}_{4} \mathrm{OH}\right]$ of $0.05,0.1$, and $0.3 \mathrm{~mol} \mathrm{dm}^{-3}$ were carried out in order to produce modified PCCs with distinct silica contents. PCCs with 11, 21, and 29 wt \% of silica, respectively, were obtained, as determined by thermogravimetric analysis. From the thermogravimetric plots, the amount of silica in the modified PCC materials was calculated as follows (wt \%): $100-\left[\right.$ weight loss $\left.\left(580-900{ }^{\circ} \mathrm{C}\right) \times 100.1 / 44.0\right]-$ [weight loss $\left.\left(30-200{ }^{\circ} \mathrm{C}\right)\right]-[$ PCC impurities percentage $]$. In this formula, the term [weight loss $\left(580-900{ }^{\circ} \mathrm{C}\right) \times 100.1 /$ 44.0] estimates, as mentioned above, the relative amount of calcium carbonate in the material. The term [weight loss (30$\left.200{ }^{\circ} \mathrm{C}\right)$ ] is mainly due to the water presence and the term [PCC impurities percentage] is known from the thermogravimetric analysis of the unmodified PCC.

Thermogravimetric analysis was performed in a TGA-50 Shimadzu thermobalance under air atmosphere between 25 and $900{ }^{\circ} \mathrm{C}$ with a heating rate of $10{ }^{\circ} \mathrm{C} / \mathrm{min}$. Zeta potential was determined using a Zetasizer Nano ZS from Malvern Instruments. The ISO brightness of the PCC and modified PCCs was measured according to the SCAN-P 89:03 test method.

2.2. Retention Tests in the Dynamic Drainage Analyzer. Drainage tests were performed in order to select the most appropriate retention agent (based on minimum mineral loss and drainage time). Due to the complexity of the flocculation processes, which includes charge neutralization, patching, and bridging mechanisms, three different commercial retention agents were tested: a linear cationic polyacrylamide (L-CPAM), a branched cationic polyacrylamide (B-CPAM), and an anionic polyacrylamide (APAM). The experiments were carried out with suspensions of the unmodified PCC and with the modified PCC having the higher silica content (29 wt \%).

Before carrying out the drainage tests several suspensions and solutions of the different components required were prepared. A Eucalyptus globulus bleached kraft pulp refined up to $33^{\circ} \mathrm{SR}$ was used as the cellulosic fiber source. After disintegration it was diluted to a consistency of $1 \%$ in demineralized water. Aqueous suspensions of the unmodified or modified PCCs containing $1 \mathrm{wt} \%$ of filler were prepared by adding water to PCC and stirring, first with magnetic stirring $(20 \mathrm{~min})$ and after with ultrasound $(15 \mathrm{~min}, 50 \mathrm{kHz})$ before use. Alkenyl succinic anhydride (ASA) supplied by the industry was used as the internal sizing agent after stabilization by adding it to a $3 \%$ starch suspension standing at $60{ }^{\circ} \mathrm{C}$, which was prepared as previously reported. ${ }^{25}$ A $0.025 \%$ aqueous solution of each retention agent was prepared by dissolving the solid (L-CPAM, APAM) or by diluting the stock solution (BCPAM) in demineralized water.

Drainage tests were performed in a Dynamic Drainage Analyzer (DDA, AB Akribi Kemikonsulter, Sweden) with formulations containing fiber, PCC (unmodified or modified with silica), ASA, starch, and the retention agent. Reference tests without retention agent, and without ASA, starch and retention agent, were also performed. A 60-mesh screen was used and a constant vacuum of $300 \mathrm{mbar}$ and stirring of 800 rpm was applied. The amounts added (wt \%) were 79.1, 19.8, 1.0, 0.1, and 0.02 for fiber, filler, starch, ASA, and retention agent, respectively. These were selected based on the industrial scale experience and set to obtain a maximum level of filler incorporation in the pad of $20 \mathrm{wt} \%$ (assuming the ideal situation of no filler losses during the pad formation). A mixture of the fiber suspension $(400 \mathrm{~mL})$ with the PCC suspension $(100 \mathrm{~mL})$ was added to the DDA vessel. After $120 \mathrm{~s}$ of mechanical stirring, the starch/ASA mixture (at ca. $60{ }^{\circ} \mathrm{C}$ ) was added. The retention agent $(4 \mathrm{~mL})$ was finally added after a total time of $290 \mathrm{~s}$ and allowed to stir for $10 \mathrm{~s}$ more. The stirring was stopped, the drainage valve was opened, and the drainage time was recorded. Afterward, the wet pad was collected and calcined at $525{ }^{\circ} \mathrm{C}$ for $16 \mathrm{~h}$ to determine the PCC or PCC-silica retention (adapted from the Tappi Standard T 211 om-93). All drainage tests were run at least in duplicate.

2.3. Handsheets Production and Papermaking Properties. Handsheets were produced in a batch laboratory sheet former (255/SA model, MAVIS) using a 120-mesh screen with the same amounts and contact times similar to those used in the aforementioned drainage tests. The aim was to achieve a basis weight of $80 \mathrm{~g} / \mathrm{m}^{2}$ and a target filler content in the handsheets of $20 \mathrm{wt} \%$. The fiber, PCC (or modified PCC), starch, and ASA were mixed as in the DDA and the retention agent was then added and let to stir for $5 \mathrm{~s}$. The mixture was transferred into the former and after $10 \mathrm{~s}$ of air agitation, drainage was performed. The total contact time of the retention agent with the other components in the mixture was ca. $30 \mathrm{~s}$. The sheets were collected from the web and pressed, dried, and conditioned according to the ISO 5269-1 standard. At least two series of experiments were run for each formulation. The structural (basis weight, density, bulk, thickness, air permeability, surface roughness), mechanical (tensile, stiffness, tear and burst resistance), and optical (light scattering, opacity, brightness) properties were measured according to the corresponding ISO Standard Test Methods. The internal bond strength was measured using the corresponding Tappi Standard. Finally, the handsheets were also calcined at $525^{\circ} \mathrm{C}$ to determine the filler retention. Energy dispersive X-ray (EDX) analyses of handsheets were performed with an energy dispersive X-ray spectrometer from Oxford Instruments (model $\mathrm{X}$-Max). The samples were previously sputter coated with gold before the EDX spectra acquisition.

2.4. Filler Retention. After calcination at $525{ }^{\circ} \mathrm{C}$ of the DDA pad or the handsheets the residues are constituted by calcium carbonate, which is not decomposed at this temperature, and by a minor amount of the PCC impurities/ degradation products from PCC impurities. For those with PCC-silica, the samples after $525{ }^{\circ} \mathrm{C}$ include, in addition, silica, which underwent some condensation of hydroxyl groups during thermal treatment. Thus, to correct the losses intrinsically due to the PCC and silica-coated PCC occurring during the thermal treatment at $525{ }^{\circ} \mathrm{C}$, experiments were carried out in the furnace using only the unmodified PCC and 
the silica-coated PCC. For the unmodified PCC the weight loss correction factor due to the impurities degradation was found to be $2.2 \%$. For the PCCs modified with 11,21 , and 29 wt \% of silica, the correction factor due to solvent removal, impurities degradation, and condensation of hydroxyl groups was 6.0, 7.9, and $10.2 \%$, respectively. Considering these values, the retentions (\%) of PCC and PCC-silica were calculated as follows: [weight at $525^{\circ} \mathrm{C} /($ (weight of initial PCC) $\times(100-$ correction factor) $)] \times 10^{4}$.

\section{RESULTS AND DISCUSSION}

3.1. Synthesis of the New Silica-Modified PCC Materials. The synthesis and characterization of silicamodified PCC was thoroughly described in a previous paper. ${ }^{24}$ By performing the hydrolysis/condensation of TEOS in ethanol/water solutions $(\sim 9: 1, v / v)$ under alkaline conditions, using ammonia as the catalyst, at a temperature of ca. $20{ }^{\circ} \mathrm{C}$, the formation of a dense film of highly branched silica was clearly detected at the surface of PCC, as demonstrated by FTIR, ${ }^{29}$ Si MAS NMR, SEM/EDX, and thermogravimetric analysis of the new solid materials. ${ }^{24}$ For the present work, reactions were carried out with ammonia concentrations of $0.05,0.1$, and $0.3 \mathrm{M}$ and the previous established procedure ${ }^{24}$ was up scaled $10-15$ times. From these reactions PCC-based materials with silica average amounts of 11, 21, and 29 wt \% (based on thermogravimetric analysis, Figure 1) were obtained. The reproducibility of the synthesis

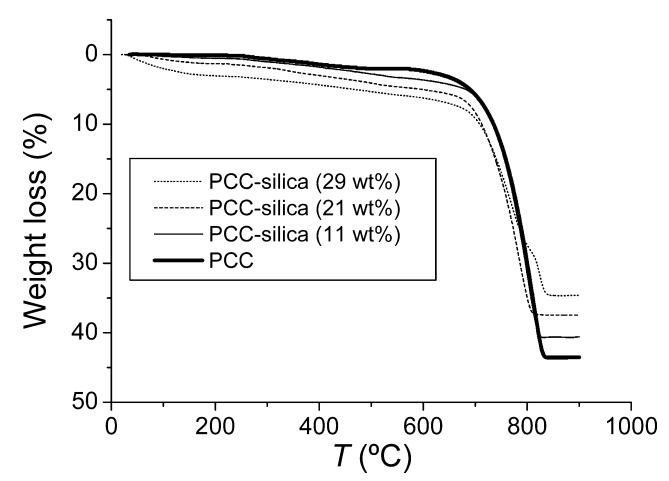

Figure 1. Thermograms of the original PCC and of PCC modified with 11,21 , and 29 wt $\%$ of silica.

was good. For instance, 5 runs of the reaction with ammonia concentration of $0.3 \mathrm{M}$ gave an average silica content of $28.1 \mathrm{wt}$ $\%$ with a standard deviation of 1.3 wt \%.

The main results regarding zeta potential and brightness of the modified PCCs are shown in Table 1. The zeta potential of the silica-modified PCCs showed values in the range of -30 to $-40 \mathrm{mV}$ while for the initial PCC it was $+7 \mathrm{mV}$. Thus, the presence of silica at the surface of the PCC crystals turned the PCC zeta potential to negative values. This was somewhat expected since the ionization of the hydroxyl groups from the

Table 1. Zeta Potential and Brightness of the PCC and Modified PCCs

$\begin{array}{ccc}\text { silica amount }(\mathrm{wt} \%) & \text { zeta potential }(\mathrm{mV}) & \text { brightness }(\%) \\ 0 & +7 & 95.3 \\ 11 & -32 & \\ 21 & -34 & 96.2 \\ 29 & -35 & 95.5\end{array}$

silica surface releases protons to the medium at alkaline $\mathrm{pH}$ (i.e., much higher than the silica isoelectric point). On the other hand, brightness, which is an important parameter for papermaking and should be as high as possible, did not vary significantly with the surface modification. In fact, the value measured for the PCC brightness was of $95.3 \%$ while for the PCC-based materials with different silica content the brightness was in the range of $95.5-96.2 \%$. It should be noted that the modification of the PCC particles by silica using sol-gel method does not introduce major alterations in the dimensions and aggregation of the individual scalenohedral calcium carbonate crystals, as shown previously by SEM and particle size determinations by laser diffraction spectroscopy. ${ }^{24}$ When the new produced materials are added to water the release of silica from the PCC surface to the suspension is unlikely, since their particle size distribution was very similar to that of unmodified PCC and no evidence for the presence of spherical silica particles of small size was found in the size distribution plot. $^{24}$

3.2. Pulp Drainage in the Presence of PCC-Silica Filler. The filler retention and drainage time results for the pulp suspensions containing the unmodified PCC and silicacoated (29 wt \%) PCC are listed in Table 2. As mentioned,

Table 2. Retention Values of PCC and PCC-Silica and Drainage Times Obtained Using the Dynamic Drainage Analyzer $^{a}$

\begin{tabular}{|c|c|c|c|c|}
\hline & \multicolumn{2}{|c|}{ PCC } & \multicolumn{2}{|c|}{ PCC-silica (29 wt \%) } \\
\hline & $\begin{array}{l}\text { retention } \\
(\%)\end{array}$ & time $(\mathrm{s})$ & $\begin{array}{l}\text { retention } \\
(\%)\end{array}$ & time $(s)$ \\
\hline $\begin{array}{l}\text { blank }(=\text { fiber }+ \\
\text { filler })\end{array}$ & $83 \pm 2$ & $4.8 \pm 0.0$ & $72 \pm 1$ & $6.2 \pm 0.1$ \\
\hline+ starch + ASA & $84 \pm 1$ & $5.5 \pm 0.5$ & $87 \pm 1$ & $5.6 \pm 0.1$ \\
\hline $\begin{array}{l}+ \text { starch }+ \text { ASA + L- } \\
\text { CPAM }\end{array}$ & $94 \pm 0.3$ & $4.7 \pm 0.1$ & $93 \pm 0.3$ & $4.6 \pm 0.2$ \\
\hline$+\underset{\text { CPAM }}{\text { starch }+ \text { ASA + B- }}$ & $90 \pm 2$ & $4.0 \pm 0.4$ & $86 \pm 1$ & $3.4 \pm 0.1$ \\
\hline $\begin{array}{l}+ \text { starch + ASA + } \\
\text { APAM }\end{array}$ & $96 \pm 1$ & $14.5 \pm 1.6$ & $90 \pm 1$ & $16.8 \pm 1.9$ \\
\hline
\end{tabular}

${ }^{a}$ All formulations evaluated in the DDA included fiber and filler. LCPAM refers to linear cationic polyacrylamide, B-CPAM refers to branched cationic polyacrylamide, and APAM refers to anionic polyacrylamide.

three retention agents were tested in order to find the most suitable one to be used, namely two cationic polyacrylamides (L-CPAM and B-CPAM) and one anionic polyacrylamide (APAM). For the suspensions with only fiber and filler, i.e., without any other additive in the furnish, the filler retention decreased when using the modified filler (from 83 to $72 \%$ ). However, for a furnish containing fiber, filler, starch, and ASA, the filler retention values in the DDA were roughly similar for the modified and unmodified PCC (84-87\%). With the addition of polyacrylamides as retention agents all the filler retention values increased, as expected, reaching values higher than $90 \%$, even though the retention values of the modified filler were lower than those of the unmodified PCC. Regarding the silica-modified PCC, the highest filler retention value was obtained with the linear cationic polyacrylamide (93\%). The electrostatic interactions seem to dominate the polyelectrolyte effect in retention since the fibers and the modified PCC particles are negatively surface charged and the linear anionic charged APAM leads to a smaller retention value than the linear 

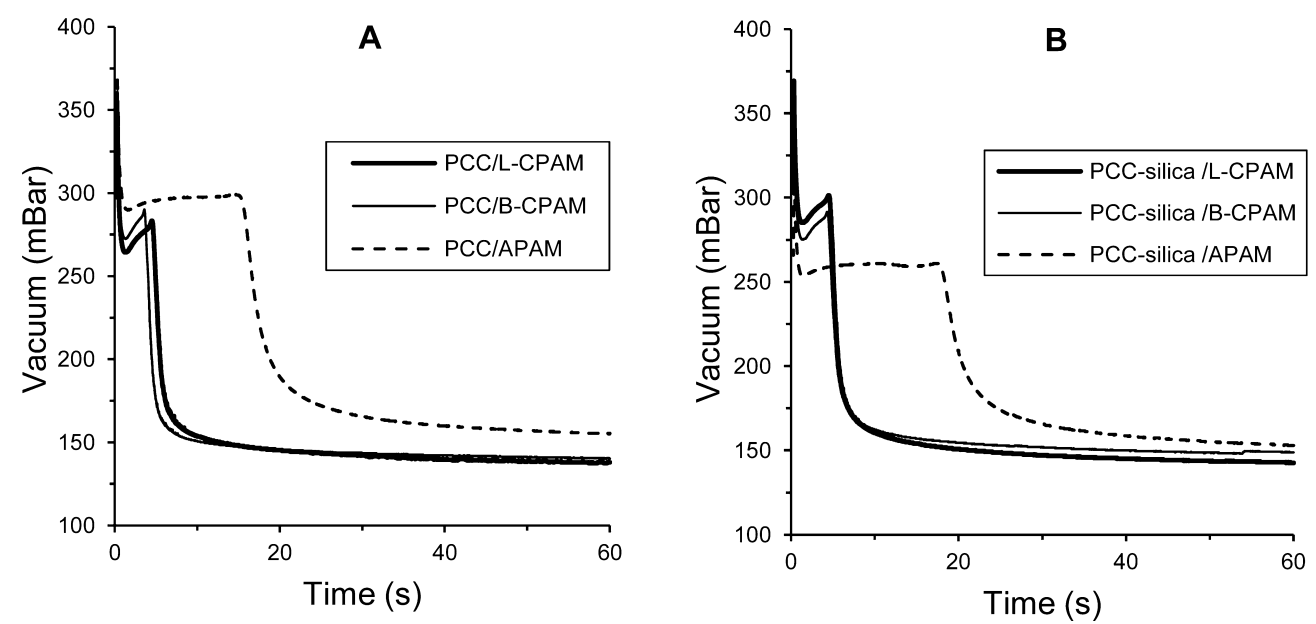

Figure 2. Drainage behavior of the pulp suspensions with (A) unmodified PCC and (B) PCC modified with 29 wt \% of silica, using three different retention agents.

cationic charged CPAM. Besides, as depicted in Figure 2, the drainage time, evaluated by the DDA, is much higher when APAM is used, which is detrimental for papermaking. On the other hand, considering the higher retention value obtained with the linear cationic polyacrylamide comparing to that of the branched one, it is legitimate to conclude that bridging also plays an important role on the flocculation mechanism. ${ }^{26,27}$ Therefore, from the results of both the filler retention and drainage time, the linear CPAM retention agent is the best choice for the new modified fillers and was thus used for the further papermaking tests.

3.3. Papermaking Properties of the New Modified PCCs. Laboratorial handsheets were made with fibers, unmodified or modified PCC, ASA, starch, and retention agent (L-CPAM) and evaluated in terms of the most important structural, optical, and strength properties. The main results of the handsheets prepared with the different fillers are listed in Table 3. The filler retention varied between 78 and $83 \%$, making it possible to compare the papermaking properties of the different handsheets (which, besides, have identical basis weight). In agreement with the high values of filler retention in the handsheets no significant levels of Si were detected in the papermaking filtrates analyzed by atomic absorption spectros-

Table 3. Papermaking Properties of the Handsheets Produced with Different Fillers

$\begin{array}{llccc} & \text { PCC } & \begin{array}{c}\text { PCC-silica } \\ (11 \text { wt \%) }\end{array} & \begin{array}{c}\text { PCC-silica } \\ (21 \text { wt \% })\end{array} & \begin{array}{c}\text { PCC-silica } \\ (29 \text { wt \%) }\end{array} \\ \text { filler retention }(\%) & 83 & 83 & 78 & 78 \\ \text { basis weight }\left(\mathrm{g} / \mathrm{m}^{2}\right) & 84.0 & 83.5 & 83.7 & 82.9 \\ \text { bulk }\left(\mathrm{cm}^{3} / \mathrm{g}\right) & 1.7 & 1.6 & 1.6 & 1.6 \\ \text { air resistance } & 2.0 & 2.0 & 2.3 & 2.2 \\ \quad(\text { Gurley, s/100 mL) } & & & & \\ \text { roughness }(\mathrm{smooth} \mathrm{side,} & 225 & 235 & 227 & 220 \\ \text { mL } / \mathrm{min}) & & & & \\ \text { brightness } \mathrm{R} 457 \mathrm{C} & 88.0 & 87.6 & 88.3 & 87.5 \\ \text { opacity }(\%) & 88.6 & 87.9 & 87.3 & 85.7 \\ \text { light scattering }\left(\mathrm{m}^{2} / \mathrm{kg}\right) & 56.2 & 53.2 & 52.0 & 46.6 \\ \text { tensile index }(\mathrm{N} \cdot \mathrm{m} / \mathrm{g}) & 33.6 & 34.6 & 36.3 & 38.1 \\ \text { tensile stiffness }(\mathrm{kN} / \mathrm{m}) & 481 & 471 & 475 & 499 \\ \text { burst index }\left(\mathrm{kPa} \cdot \mathrm{m}^{2} / \mathrm{g}\right) & 1.9 & 2.2 & 2.2 & 2.3 \\ \text { tear index }\left(\mathrm{mN} \cdot \mathrm{m}^{2} / \mathrm{g}\right) & 7.3 & 7.6 & 7.7 & 7.8 \\ \text { Scott bond }\left(\mathrm{J} / \mathrm{m}^{2}\right) & 217 & 311 & 288 & 303\end{array}$

copy (maximum increments of $1-2 \mathrm{mg} / \mathrm{L}$ ). The EDX analyses (Figure 3) of the handsheets confirmed the presence of $\mathrm{C}, \mathrm{O}$, $\mathrm{Ca}$, and silicon for the handsheets prepared with the new silicacontaining fillers.

Regarding the structural properties, there were no relevant differences when using the PCC-silica fillers in comparison to the unmodified PCC. On the contrary, some of the optical properties were affected with the PCC modification. In fact the opacity, and particularly the light scattering coefficient, decreased with the increase of the silica amount at the surface of the PCC particles (from $56.2 \mathrm{~m}^{2} / \mathrm{kg}$ with no silica up to 46.6 $\mathrm{m}^{2} / \mathrm{kg}$ for the PCC-silica with $29 \%$ of silica). However, the handsheets brightness was not affected, in agreement with the similar brightness values of PCC and PCC-silica particles (Section 3.1). The most important result is the positive effect of the PCC surface modification on the handsheets mechanical resistances. In fact, when compared to the original uncoated PCC, tensile, burst, and tear indexes increased more than $13 \%$, $20 \%$, and $7 \%$, respectively, with the use of PCC modified with $29 \%$ of silica. The increase of the internal resistance as evaluated by the Scott bond is particularly relevant. Other measured mechanical properties showed similar trends.

From the results, it is evident that the hydrogen bonding between the cellulosic fibers and the hydroxyl groups located at the surface of the silica film coating the calcium carbonate crystals, during the sheet formation, enhances fiber-to-filler bonding. This type of interaction was reported before for cellulose-silica hybrids. ${ }^{28}$ These intermolecular interactions do not occur between the unmodified PCC crystals and fibers and compensate the fact that both PCC-silica material and cellulosic fibers show a negative zeta potential. In addition, the presence of the cationic polyacrylamide retention agent and its affinity to both the modified filler and lignocellulosic fibers by electrostatic forces also helps to obtain a stronger fiber-filler structure. The results of Table 3 also show that the improvement of the strength properties with the silica content is limited by the decrease in opacity/light scattering.

\section{CONCLUSIONS}

The papermaking potential of new silica-containing PCC materials as fillers was evaluated and compared to that of unmodified PCC. Based on the filler retention and drainage time values obtained during the drainage tests performed with 

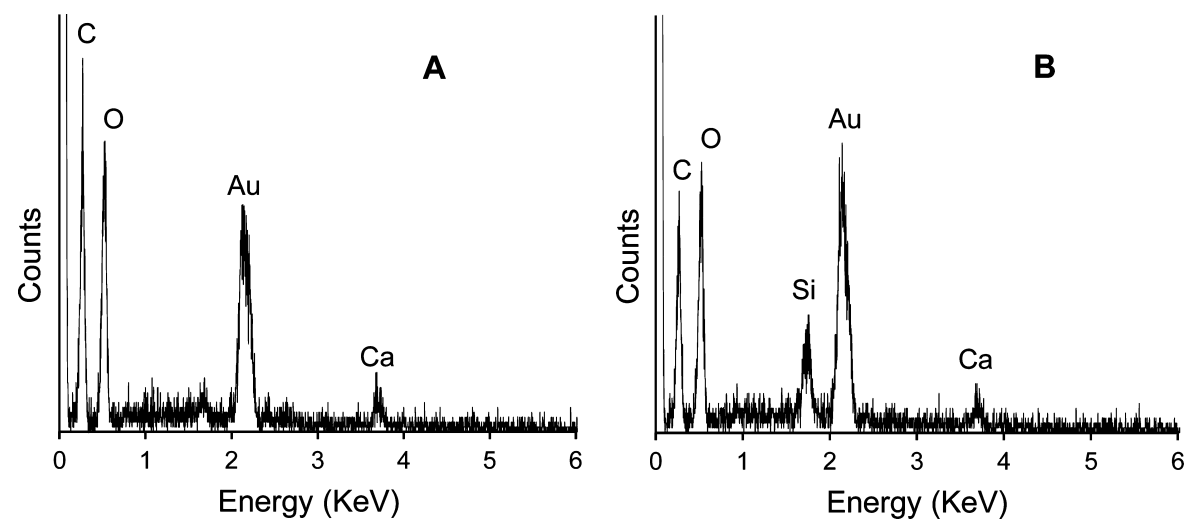

Figure 3. EDX spectra of handsheets containing PCC (A) and PCC modified with silica (29 wt \%) (B).

different polyacrylamides, a linear cationic polyacrylamide was selected as the most adequate retention agent. Good filler retention values, similar to that of the original material (ca. $80 \%)$, were obtained with the new fillers. An improvement of the paper strength properties, for instance tensile and internal bonding, was found by using PCC-silica composites. The main handsheets structural properties and the brightness were not affected by the use of the new modified fillers. The papermaking results suggest that a silica film coating the calcium carbonate crystals could be beneficial for the fiber-tofiller bonding. The additional cost of using silica could therefore be mitigated by the increase of the strength properties and subsequent improvement of the paper performance at the printing/copying processes. A new possibility to increase the filler amount in papermaking is thus envisaged.

\section{AUTHOR INFORMATION}

\section{Corresponding Author}

*E-mail: jafgas@eq.uc.pt (J.A.F.G.) and paulo@eq.uc.pt (P.J.F.).

\section{Notes}

The authors declare no competing financial interest.

\section{REFERENCES}

(1) Raymond, L.; Turcotte, R.; Gratton, R. The challenges of increasing filler in fine paper. Paper Technol. 2004, July, 34-40.

(2) Thorp, B. Engineered fillers: An agenda 2020 goal. Solutions People, Processes Pap. 2005, May, 45-48.

(3) Shen, J.; Song, Z.; Qian, X.; Liu, W. Modification of papermaking grade fillers: A brief review. Bioresources 2009, 4, 1190-1209.

(4) Zhao, Y.; Zeshan, H.; Ragauskas, A.; Deng, Y. Improvement of paper properties using starch-modified precipitated calcium carbonate filler. Tappi J. 2004, 2 (4), 3-7.

(5) Shen, J.; Song, Z.; Qian, X. Investigations on the preparation of starch/sodium oleate/alum modified precipitated calcium carbonate filler and its use in papermaking. Appita J. 2009, 62, 360-364, 382.

(6) Deng, Y.; Yoon, S.; Ragauskas, A.; White, D. Methods and compositions for papermaking. U.S. Patent 7,964,063 B2, 2011.

(7) Fan, H. M.; Wang, D. X.; Bai, W. R.; Liu, J. N. Starch-sodium stearate complex modified PCC filler and its application in papermaking. Bioresources 2012, 7, 3317-3326.

(8) Van Der Horst, P. M.; Sanne, E.; Andersson, K. R.; GarciaLindgren, C.; Wallberg, M.; Wannstrom, S. Filler for papermaking process. WO Patent 061793, 2005.

(9) Shen, J.; Song, Z.; Qian, X.; Yang, F. Carboxymethyl cellulose/ alum modified precipitated calcium carbonate fillers: Preparation and their use in papermaking. Carbohydr. Polym. 2010, 81, 545-553.

(10) Fairchild, G. H. Treatment of inorganic filler material for paper with polysaccharides. U.S. Patent 5,458,679, 1995.
(11) Gill, R. A. Cationic polymer-modified filler material, process for its preparation and method. Canada Patent 2037525, 1991.

(12) Laleg, M.; Collins, R.; Gagne, D.; Middleton, S. Latex-treated filler slurries for use in papermaking. WO Patent 148204, 2008.

(13) Chen, X.; Huang, R; Pelton, R. The reinforcement of calcium carbonate filled papers with phosphorus-containing polymers. Ind. Eng. Chem. Res. 2005, 44, 2078-2085.

(14) Passaretti, J. D. Acid-stabilized calcium carbonate, process for its production and method for its use in the manufacture of acidic paper. U.S. Patent 5,043,017, 1991.

(15) Tokarz, M.; Jaras, S.; Sikkar, R. Process for the preparation of an acid-resistant coating on filler particles. U.S. Patent 5,000,791, 1991.

(16) Chapnerkar, V. D.; Lasmarias, V. B.; Matur, V. K. Method for preparing acid resistant calcium carbonate pigments. U.S. Patent 5,164,006, 1992.

(17) $\mathrm{Wu}, \mathrm{K}$. T. Acid resistant calcium carbonate composition and uses therefor. U.S. Patent 5,593,488, 1997.

(18) Pang, P.; Khoultchaev, K. K.; Englezos, P. Inhibition of the dissolution of papermaking grade precipitated calcium carbonate filler. Tappi J. 1998, 81 (4), 188-192.

(19) Snowden, K. J.; Wu, K. T.; Rodriguez, J. M. Stabilized calcium carbonate composition using sodium silicate and one or more weak acids or alum and uses therefor. U.S. Patent 6,083,317, 2000.

(20) Adams, C. Jr. Silica-coated alkaline earth metal carbonate pigment. WO Patent 0026305, 2000.

(21) Jaakkola, P.; Mannu, H. Comparison of methods for stabilization of PCC against dissolution at acid papermaking conditions. Nord. Pulp Pap. Res. J. 2001, 16, 113-117.

(22) Shen, J.; Song, Z.; Qian, X.; Liu, W. A preliminary investigation into the use of acid-tolerant precipitated calcium carbonate fillers in papermaking of deinked pulp derived from recycled newspaper. Bioresources 2009, 4, 1178-1189.

(23) Shen, J.; Song, Z.; Qian, X.; Liu, W. Modification of precipitated calcium carbonate filler using sodium silicate/zinc chloride based modifiers to improve acid-resistance and use of the modified filler in papermaking. Bioresources 2009, 4, 1498-1519.

(24) Gamelas, J. A. F.; Lourenço, A. F.; Ferreira, P. J. New modified filler obtained by silica formed by sol-gel method on calcium carbonate. J. Sol-Gel Sci. Technol. 2011, 59, 25-31.

(25) Saraiva, M. S.; Gamelas, J. A. F.; de Sousa, A. P. M.; Reis, B. M; Amaral, J. L.; Ferreira, P. J. A new approach for the modification of paper surface properties using polyoxometalates. Materials 2010, 3, 201-215.

(26) Kapoor, J. K.; Jabin, S.; Bhatia, H. S.; Kapoor, N. Evaluation of cationic and anionic polyelectrolytes as a coagulants aid for water quality improvement. J. Chem. Cheml. Sci. 2011, 1, 267-275.

(27) Papermaking Science and Technology, Book 4; Gullichsen, J., Paulapuro. H., Eds.; Fapet Oy: Helsinki, Finland, 1999; Chapter 3.

(28) Gamelas, J. A. F.; Evtyugina, M. G.; Portugal, I.; Evtuguin, D. V. New polyoxometalate-functionalized cellulosic fiber/silica hybrids for environmental applications. RSC Adv. 2012, 2, 831-839. 